Article

\title{
Enzymes Catalyzing the TCA- and Urea Cycle Influence the Matrix Composition of Biofilms Formed by Methicillin-Resistant Staphylococcus aureus USA300
}

\author{
Sarah De Backer ${ }^{1}$, Julia Sabirova ${ }^{1}$, Ines De Pauw ${ }^{1}$, Henri De Greve ${ }^{2,3}$, \\ Jean-Pierre Hernalsteens ${ }^{4}\left(\mathbb{D}\right.$, Herman Goossens ${ }^{1}$ and Surbhi Malhotra-Kumar ${ }^{1, *}$ \\ 1 Department of Medical Microbiology, Vaccine \& Infectious Diseases Institute, University of Antwerp, \\ 2610 Wilrijk, Belgium; sarah.debacker@uantwerpen.be (S.D.B.); jus16@dsmz.de (J.S.); \\ ines.depauw@uantwerpen.be (I.D.P.); herman.goossens@uantwerpen.be (H.G.) \\ 2 Structural \& Molecular Microbiology, VIB-VUB Center for Structural Biology, 1050 Brussels, Belgium; \\ henri.de.greve@vub.be \\ 3 Structural Biology Brussels, Vrije Universiteit Brussel, 1050 Brussels, Belgium \\ 4 Viral Genetics, Vrije Universiteit Brussel, 1050 Brussels, Belgium; jphernal@vub.ac.be \\ * Correspondence: surbhi.malhotra@uantwerpen.be; Tel.: +32-3-265-27-52
}

Received: 27 July 2018; Accepted: 25 October 2018; Published: 29 October 2018

check for updates

\begin{abstract}
In methicillin-sensitive Staphylococcus aureus (MSSA), the tricarboxylic acid (TCA) cycle is known to negatively regulate production of the major biofilm-matrix exopolysaccharide, PIA/PNAG. However, methicillin-resistant $S$. aureus (MRSA) produce a primarily proteinaceous biofilm matrix, and contribution of the TCA-cycle therein remains unclear. Utilizing USA300-JE2 Tn-mutants (NARSA) in genes encoding TCA- and urea cycle enzymes for transduction into a prolific biofilm-forming USA300 strain (UAS391-Ery ${ }^{\mathrm{s}}$ ), we studied the contribution of the TCA- and urea cycle and of proteins, eDNA and PIA/PNAG, to the matrix. Genes targeted in the urea cycle encoded argininosuccinate lyase and arginase $(\arg H:: T n$ and $\operatorname{roc} F:: T n)$, and in the TCA-cycle encoded succinyl-CoA synthetase, succinate dehydrogenase, aconitase, isocitrate dehydrogenase, fumarate hydratase class II, and citrate synthase II (sucC::Tn, sdhA/B::Tn, acnA::Tn, icd::Tn, fumC::Tn and gltA::Tn). Biofilm formation was significantly decreased under no flow and flow conditions by $\operatorname{argH}::$ Tn, fumC::Tn, and $s d h A / B:: T n$ (range $\mathrm{OD}_{492}$ 0.374-0.667; integrated densities 2.065-4.875) compared to UAS391-Ery ${ }^{S}\left(\mathrm{OD}_{492}\right.$ 0.814; integrated density 10.676) $(p \leq 0.008)$. Cellular and matrix stains, enzymatic treatment (Proteinase K, DNase I), and reverse-transcriptase PCR-based gene-expression analysis of fibronectin-binding proteins $(f n b A / B)$ and the staphylococcal accessory regulator (sarA) on pre-formed UAS391-Erys and Tn-mutant biofilms showed: (i) < 1\% PIA/PNAG in the proteinaceous/eDNA matrix; (ii) increased proteins under no flow and flow in the matrix of Tn mutant biofilms (on average 50 and $51( \pm 11) \%$ ) compared to UAS391-Erys (on average 22 and 25 $( \pm 4) \%)(p<0.001)$; and (iii) down- and up-regulation of $f n b A / B$ and sar $A$, respectively, in Tn-mutants compared to UAS391-Ery ${ }^{S}$ (0.62-, 0.57-, and 2.23-fold on average). In conclusion, we show that the biofilm matrix of MRSA-USA300 and the corresponding Tn mutants is PIA/PNAG-independent and are mainly composed of proteins and eDNA. The primary impact of TCA-cycle inactivation was on the protein component of the biofilm matrix of MRSA-USA300.
\end{abstract}

Keywords: MRSA; MSSA; SCCmec; $\operatorname{argH}$; sdhB; sdhA; fumC; tricarboxylic acid cycle; fnbA; fnbB; $\operatorname{sar} A$; arginine; fumarate; malate 


\section{Introduction}

Nosocomial and community-acquired infections caused by Staphylococcus aureus range from superficial to life-threatening [1]. The pathogenic ability of S. aureus is greatly facilitated by its capacity to form biofilms, sessile microbial communities that remain embedded in an extracellular polymeric glycocalyx (matrix) or slime layer [2]. Interestingly, recent studies have highlighted differences in biofilm formation between methicillin-sensitive $S$. aureus (MSSA) and their (multi-) drug resistant counterpart, methicillin-resistant $S$. aureus (MRSA) [3,4]. In MSSA, the primary polysaccharide that forms the biofilm matrix is encoded by the icaADBC operon and is known as polysaccharide intercellular adhesin PIA or poly-N-acetylglucosamine PNAG [5]. On the other hand, MRSA exhibits a primarily proteinaceous biofilm matrix, with very little contribution of PIA/PNAG [6], that is mediated by adhesins such as the fibronectin binding proteins FnbpA/B [7]. In addition, recent reports also show an important contribution of extracellular DNA (eDNA) to the MRSA biofilm matrix [8]. eDNA in $S$. aureus is released by cell lysis, which has been shown to be dependent on autolysins such

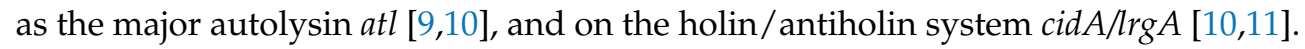

The tricarboxylic acid (TCA) cycle is a central metabolic pathway that generates energy (ATP) and precursors for biosynthesis of macromolecules like 2-oxoglutarate [12]. Its role in regulating PIA/PNAG production in staphylococcal species has been well-studied. In S. epidermidis, environmental changes that inhibited TCA-cycle activity also resulted in a massive derepression of PIA biosynthetic genes and increased PIA production [13,14]. This inverse correlation was also confirmed for MSSA in a rabbit catheter model of biofilm infection [15]. However, the contribution of the TCA-cycle, if any, to biofilm formation by MRSA remains unclear, given the primarily protein-based matrix and the lack of studies on TCA-cycle inhibition using fluorocitrate or transposon (Tn) mutants.

In this study, utilizing Tn mutants, biofilm models, and various stains and enzymes, we studied the importance of the TCA- and urea cycle for biofilm formation by MRSA-USA300 and the net contribution of proteins, eDNA and PIA/PNAG, to the matrix.

\section{Materials and Methods}

\subsection{Bacterial Strains and Growth Conditions}

The strains used in this study are shown in Table 1. Bursa aurealis transposon (Tn) insertion mutations encoding functionally non-redundant TCA- and urea cycle enzymes (Figure 1) in USA300-JE2 were obtained from the Nebraska Transposon Mutant Library (NTML, www.beiresources.org) [16]. Parental strains UAS391, UAS391-Ery ${ }^{S}$ (erythromycin resistance cured UAS391), and JE2 are all MRSA belonging to the highly virulent and widespread clonal lineage, USA300. These, as well as Tn insertion mutants, were routinely grown on Brain-Heart infusion (BHI; Becton, Dickinson and Company, Franklin Lakes, NJ, USA) supplemented with $0.1 \% \mathrm{D}(+)$-glucose monohydrate (Merck Millipore, Billerica, MA, USA) and BHI Bacto ${ }^{\mathrm{TM}}$ agar (Becton, Dickinson and Company, USA) for biofilm, transduction and complementation experiments. Lysogeny broth (LB; Becton, Dickinson and Company, USA) was used for Escherichia coli. For the Tn-carrying S. aureus transductants with the erythromycin resistance marker ermB, 5 or $10 \mu \mathrm{g} / \mathrm{mL}$ erythromycin (Sigma-Aldrich ${ }^{\circledR}$, Merck KGaA, St. Louis, MO, USA) was supplemented to the growth medium. 


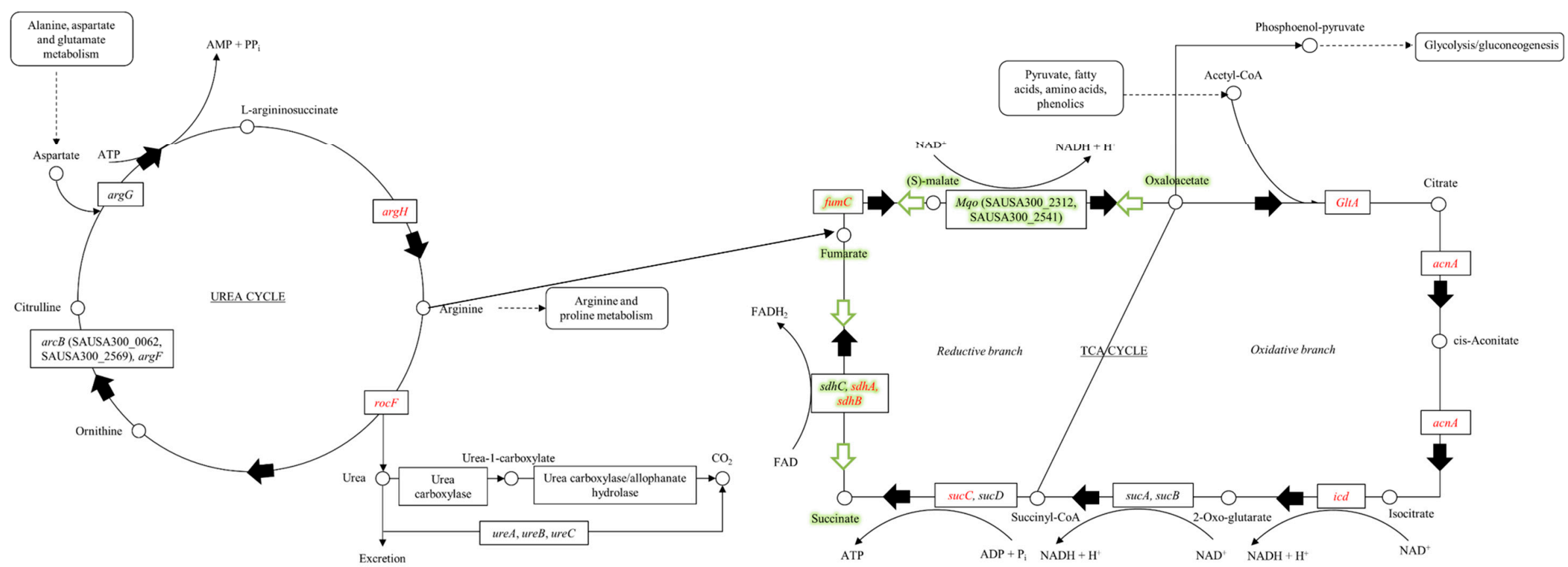

Figure 1. The urea and tricarboxylic acid (TCA)-cycles. Arginine is synthesized via the urea cycle. Carbamoyl phosphate reacts with ornithine to generate citrulline. Addition of aspartate to citrulline creates L-argininosuccinate. ATP is cleaved to AMP and pyrophosphate to drive this reaction forward. Arginine is cleaved off of L-argininosuccinate by the enzyme encoded by $\operatorname{argH}$ and can be used for protein synthesis. Hydrolysis of arginine generates ornithine and urea. Fumarate is the other product of the ArgH-catalyzed reaction and can be used in the TCA-cycle. Acetyl-CoA derived from pyruvate and other catabolic pathways enters the TCA-cycle. The acetyl group condenses with four-carbon oxaloacetate to produce citrate. Citrate rearranges to isocitrate, which is decarboxylated and forms NADH + $\mathrm{H}^{+}$by transferring $2 \mathrm{H}^{+}+2 \mathrm{e}^{-}$. 2-Oxoglutarate is decarboxylated and transfers $2 \mathrm{H}^{+}+2 \mathrm{e}^{-}$to form NADH $+\mathrm{H}^{+}$, while incorporating CoA to form succinyl-CoA. Succinate forms fumarate by transferring $2 \mathrm{H}^{+}+2 \mathrm{e}^{-}$resulting in $\mathrm{FADH}_{2}$. Water is incorporated, and oxaloacetate is formed when $2 \mathrm{H}^{+}+2 \mathrm{e}^{-}$are transferred to form $\mathrm{NADH}+\mathrm{H}^{+}$. The pathway marked in green highlights the proposed model for NADH reoxidation (Arnon-Buchanan cycle). 


\subsection{Transduction Experiments}

Nine bursa aurealis Tn mutations in candidate genes of the TCA- and urea cycles were transduced with phage $\Phi 11$ from USA300-JE2 to UAS391-Ery $\mathrm{S}$. Gene knockouts in UAS391-Ery ${ }^{\mathrm{S}}(\operatorname{argH}:: \mathrm{Tn}$, icd::Tn, acnA::Tn, gltA::Tn, rocF::Tn, fumC::Tn, sdhA::Tn, sdhB::Tn, and sucC::Tn) were constructed through phage $\Phi 11$-mediated homologous recombination of the chromosomal UAS391-Ery ${ }^{S}$ genes with mutated alleles carried by NTML USA300-JE2 Tn insertion mutants, as described in Table 1 [17].

Table 1. Bacterial strains and plasmids used during this study.

\begin{tabular}{|c|c|c|}
\hline Name & Description & Source \\
\hline \multicolumn{3}{|c|}{ Strains } \\
\hline UAS391 & $\begin{array}{l}\text { Prolific biofilm forming MRSA USA300 strain isolated from a patient with } \\
\text { an abscess in a Belgian hospital. }\end{array}$ & {$[18,19]$} \\
\hline UAS391-Ery ${ }^{S}$ & $\begin{array}{l}\text { Erythromycin-sensitive variant (loss of ermC gene) of S. aureus UAS391 } \\
\text { obtained by plasmid curing through growth at } 44^{\circ} \mathrm{C} \text {. }\end{array}$ & [17] \\
\hline JE2 & $\begin{array}{l}\text { Plasmid-cured derivative of MRSA USA300 LAC, isolated from a skin and } \\
\text { soft tissue infection in a detainee from the Los Angeles County jail. }\end{array}$ & [16] \\
\hline RN0450 (NRS135) & $\begin{array}{l}\text { MSSA strain derived by successive cycles of UV treatment of S. aureus strain } \\
\text { NCTC } 8325 \text {, curing it of phages } \Phi 11, \Phi 12 \text { and } \Phi 13 \text {. }\end{array}$ & NARSA repository \\
\hline RN0451 (NRS136) & MSSA strain derived from S. aureus strain RN0450, lysogenic for phage $\Phi 11$. & NARSA repository \\
\hline RN4220 & $\begin{array}{l}\text { Generated through UV and chemical mutagenesis of S. aureus strain RN0450 } \\
\text { and selected for transformability with DNA from E. coli (restriction deficient } \\
\text { through mutation in sau } 1 \text { hsdR). }\end{array}$ & NARSA repository \\
\hline $\mathrm{DH} 5 \alpha$ & $\begin{array}{l}\text { Escherichia coli cloning strain with multiple mutations (fhuA2 lac } \Delta U 169 \text { phoA } \\
\text { glnV44 } \Phi 80^{\prime} \text { lacZ } \triangle M 15 \text { gyrA96 recA1 relA1 endA1 thi-1 hsdR17) that enable } \\
\text { efficient transformation. }\end{array}$ & $\begin{array}{l}\text { Thermo Fisher } \\
\text { Scientific Inc., } \\
\text { Waltham, MA, USA }\end{array}$ \\
\hline $\mathrm{ATCC}^{\circledR} 6538^{\mathrm{TM}}$ & $\begin{array}{l}\text { Positive quality control for biofilm formation of } S \text {. aureus under no } \\
\text { flow conditions. }\end{array}$ & {$[20]$} \\
\hline 5374 & $\begin{array}{l}\text { Negative quality control for biofilm formation of S. aureus under no } \\
\text { flow conditions. }\end{array}$ & [18] \\
\hline $\operatorname{ATCC}^{\circledR} 25923^{\mathrm{TM}}$ & $\begin{array}{l}\text { PIA/PNAG-dependent biofilm producing strain used as positive } \\
\text { quality control during fluorescent staining and enzymatic treatment of } \\
\text { biofilm matrix. }\end{array}$ & [21] \\
\hline NE106 (NR-46649) & $\begin{array}{l}\text { JE2 Tn mutant (insertion position: 943092) in argininosuccinate lyase (argH, } \\
\text { SAUSA300_0863; 942072-943451). }\end{array}$ & NARSA repository \\
\hline NE134 (NR-46677) & $\begin{array}{l}\text { JE2 Tn mutant (insertion position: 2290057) in arginase (rocF, } \\
\text { SAUSA300_2114; 2289284-2290192). }\end{array}$ & NARSA repository \\
\hline NE427 (NR-46970) & $\begin{array}{l}\text { JE2 Tn mutant (insertion position: 1985575) in fumarate hydratase, class II } \\
\text { (fumC, SAUSA300_1801; 1984212-1985597). }\end{array}$ & NARSA repository \\
\hline NE491 (NR-47034) & $\begin{array}{l}\text { JE2 Tn mutant (insertion position: 1799416) in isocitrate dehydrogenase, } \\
\text { NADP-dependent (icd, SAUSA300_1640; 1798291-1799559). }\end{array}$ & NARSA repository \\
\hline NE569 & $\begin{array}{l}\text { JE2 Tn mutant (insertion position: 1247122) in succinyl-CoA synthetase, beta } \\
\text { subunit (sucC, SAUSA300_1138; 1246832-1247998). }\end{array}$ & NARSA repository \\
\hline NE594 (NR-47137) & $\begin{array}{l}\text { JE2 Tn mutant (insertion position: 1800430) in citrate synthase II ( } \mathrm{glt} A \text {, } \\
\text { SAUSA300_1641; 1799608-1800729). }\end{array}$ & NARSA repository \\
\hline NE626 (NR-47169) & $\begin{array}{l}\text { JE2 Tn mutant (insertion position: 1145819) in succinate dehydrogenase, } \\
\text { flavoprotein subunit (sdhA, SAUSA300_1047; 1145459-1147225). }\end{array}$ & NARSA repository \\
\hline NE808 (NR-47351) & $\begin{array}{l}\text { JE2 Tn mutant (insertion position: 1147490) in succinate dehydrogenase } \\
\text { iron-sulfur subunit (sdhB, SAUSA300_1048; 1147225-1148040). }\end{array}$ & NARSA repository \\
\hline NE861 (NR-47404) & $\begin{array}{l}\text { JE2 Tn mutant (insertion position: 1367722) in aconitate hydratase (acnA, } \\
\text { SAUSA300_1246; 1367131-1369836). }\end{array}$ & NARSA repository \\
\hline \multicolumn{3}{|c|}{ Plasmids } \\
\hline pALC2073 & $\begin{array}{l}\text { Contains the pSK } 236 \text { vector, with the tet } R \text {-gene and the } x y l / \text { tet } O \text { promotor, } \\
\text { originating from } \mathrm{pWH} 35 \text {. }\end{array}$ & [22] \\
\hline
\end{tabular}


Table 1. Cont.

\begin{tabular}{|c|c|c|}
\hline Name & Description & Source \\
\hline pGV5990 & $\begin{array}{l}\operatorname{argH} \text { gene amplified with primers ArgH-1 and ArgH-2 and cloned in the } \\
\text { EcoRI site of pALC2073 via Gibson cloning. }\end{array}$ & \\
\hline pGV5992 & $\begin{array}{l}\text { gltA gene amplified with primers GltA-1 and GltA-2 and cloned in the EcoRI } \\
\text { site of pALC2073 via Gibson cloning. }\end{array}$ & \\
\hline pGV5994 & $\begin{array}{l}\text { icd gene amplified with primers Icd-1 and Icd-2 and cloned in the EcoRI site } \\
\text { of pALC } 2073 \text { via Gibson cloning. }\end{array}$ & \\
\hline pGV5996 & $\begin{array}{l}\text { sdhB gene amplified with primers SdhB-1 and SdhB-2 and cloned in the EcoRI } \\
\text { site of pALC2073 via Gibson cloning. }\end{array}$ & \\
\hline pGV5998 & $\begin{array}{l}\text { sucC gene amplified with primers SucC-1 and SucC-2 and cloned in the EcoRI } \\
\text { site of pALC2073 via Gibson cloning. }\end{array}$ & \\
\hline pGV5999 & $\begin{array}{l}\text { gltA \& icd genes (operon of two genes; } 1 \text { st gene } g l t A \& \text { 2nd gene } i c d \text { ) } \\
\text { amplified with primers GltA-1 and Icd-2 and cloned in the EcoRI site of } \\
\text { pALC2073 via Gibson cloning. }\end{array}$ & This study \\
\hline pGV6000 & $\begin{array}{l}\text { sucC genes (operon of two genes) amplified with primers SucC-1 and SucC-3 } \\
\text { and cloned in the EcoRI site of pALC2073 via Gibson cloning. }\end{array}$ & \\
\hline pGV6001 & $\begin{array}{l}\text { sdhA gene amplified with primer SdhA-1 and SdhA-2 and cloned in the EcoRI } \\
\text { site of pALC2073 via Gibson cloning. }\end{array}$ & \\
\hline pGV6002 & $\begin{array}{l}\text { sdhA (2nd gene in operon of } 3 \text { genes) \& sdhB (3rd gene in operon of } 3 \text { genes) } \\
\text { genes amplified with primers SdhA- } 1 \text { and SdhB-2 and cloned in the EcoRI } \\
\text { site of pALC } 2073 \text { via Gibson cloning. }\end{array}$ & \\
\hline pGV6003 & $\begin{array}{l}\text { rocF gene amplified with primers RocF-1 and RocF-2 and cloned in the EcoRI } \\
\text { site of pALC2073 via Gibson cloning. }\end{array}$ & \\
\hline pGV6005 & $\begin{array}{l}\text { fumC gene amplified with primers FumC-1 and FumC-2 and cloned in the } \\
\text { EcoRI site of pALC2073 via Gibson cloning. }\end{array}$ & \\
\hline pGV6007 & $\begin{array}{l}\text { acnA gene amplified with primers AcnA-1 and AcnA-2 and cloned in the } \\
\text { EcoRI site of pALC2073 via Gibson cloning. }\end{array}$ & \\
\hline
\end{tabular}

\subsection{Growth Rate Analysis}

To exclude the possibility of changes in biofilm mass due to a pleiotropic effect on the bacterial growth rate, an overnight grown culture of the Tn mutants or UAS391-Ery ${ }^{S}$ was diluted until a concentration of $0.5 \mathrm{McF}$ arland and $20 \mu \mathrm{L}$ was added to $180 \mu \mathrm{L}$ fresh BHI-medium in a 96-well microtiter plate (CELLSTAR ${ }^{\circledR} 96$ Well Plate Flat Bottom (polystyrene), Greiner Bio-One, Austria). The optical density of each well was measured with a spectrophotometer (MultiSkan ${ }^{\mathrm{TM}}$ GO Microplate Spectrophotometer, Thermo Fisher Scientific Inc., Waltham, MA, USA) using SkanIt ${ }^{\mathrm{TM}}$ software during a course of $24 \mathrm{~h}$ at $37^{\circ} \mathrm{C}$ (measurements were taken every $15 \mathrm{~min}$, at $600 \mathrm{~nm}$ with shaking at $5 \mathrm{~Hz}$ and an amplitude of $15 \mathrm{~mm}$ ). Growth rates were calculated based on the exponential portion of the curve, the maximum culture density, and the duration of the growth lag phase using GrowthRates software [23]. In total, 96 measurements were made and the growth pattern of each mutant or UAS391-Ery ${ }^{\mathrm{S}}$ was measured in 8 different wells.

\subsection{Quantitative Biofilm Assay under Static (No Flow) Conditions}

UAS391-Ery $^{\text {S }}$, Tn and complemented mutants were studied as 24 h-old biofilms under flow or no flow conditions as described [18] with one modification; washing to remove planktonic bacteria was performed by gently submerging the plate in a tub of $1 \times$ PBS (Thermo Fisher Scientific Inc., Waltham, MA, USA). OD values were measured at $492 \mathrm{~nm}$ (Multiskan FC photometer, Thermo Fisher Scientific Inc., Waltham, MA, USA), normalized to the blank and compared to simultaneously run MRSA ATCC reference strains 6538 and 5374 (positive and negative control, respectively), as well as UAS391-Ery ${ }^{\mathrm{S}}$. The assay was performed on three distinct days, each time on three different plates and control strains, UAS391-Ery ${ }^{\mathrm{S}}$ as well as Tn and complementation mutants on the same plate were added in 6 different wells. 


\subsection{Quantitative Biofilm Assay under Flow (Dynamic) Conditions}

All Tn and complemented mutants as well as UAS391-Ery ${ }^{\mathrm{S}}$ were also tested for biofilm formation under dynamic conditions in the Bioflux ${ }^{\mathrm{TM}}$ system using glass 48-well plates (Fluxion Biosciences Inc., Alameda, CA, USA), as described by Reference [17]. Imaging was performed with a high-end fluorescence Carl Zeiss ${ }^{\mathrm{TM}}$ microscope (Axio Observer ${ }^{\circledR}$ with Cell Observer SD, ApoTome.2, LSM710, Göttingen, Germany) using ZEN pro 2012 software (Zeiss Efficient Navigation ${ }^{\circledR}$, Göttingen, Germany). Actual fluorescence quantification of the obtained images was performed using the program ImageJ (Image Processing and Analysis in Java), which measured integrated density (http://imagej.nih.gov/). The assay was performed on two distinct days. Control strains, UAS391-Erys, as well as Tn and complemented mutants on the same plate were added in duplicate.

\subsection{Analysis of Biofilm Matrix Composition}

Additionally, UAS391-Ery ${ }^{\mathrm{S}}$, Tn and complemented mutants grown under flow and no flow conditions were studied for differences in cell densities and viability, as well as matrix composition using LIVE/DEAD ${ }^{\mathrm{TM}}$ (BacLight ${ }^{\mathrm{TM}}$ Bacterial Viability Kit), SYPRO ${ }^{\circledR}$ Ruby (FilmTracer ${ }^{\mathrm{TM}}$ SYPRO $^{\circledR}$ Ruby Biofilm Matrix Stain), or wheat germ agglutinin (WGA) (Wheat Germ Agglutinin, Texas Red ${ }^{\mathrm{TM}}-\mathrm{X}$ Conjugate) fluorescent stains (Thermo Fisher Scientific Inc., Waltham, MA, USA). LIVE/DEAD ${ }^{\mathrm{TM}}$ stain consists of SYTO ${ }^{\mathrm{TM}} 9$ which stains the entire cell mass green followed by propidium iodide which will only stain the dead or dying cells with a compromised membrane (red). WGA Texas Red ${ }^{{ }^{\mathrm{TM}}-X}$ C Conjugate binds to sialic acid and $N$-acetylglucosaminyl residues of PIA/PNAG, and FilmTracer ${ }^{\text {TM }}$ SYPRO ${ }^{\circledR}$ Ruby Biofilm Matrix Stain labels most classes of proteins, such as glycoproteins, phosphoproteins, lipoproteins, calcium binding proteins, and fibrillar proteins. Briefly, after 24 (no flow) or $17 \mathrm{~h}$ (flow) growth and rinsing with either $1 \times$ PBS (no flow) or $0.9 \%$ sodium chloride (flow) to remove planktonic cells, biofilms were stained and microscopically visualized using the ImageJ program for data measurements, as explained before. Under no flow conditions (used for quantification), the assay was performed on three distinct days, each time on three different plates and control strains, UAS391-Erys ${ }^{S}$ as well as mutants on the same plate were added in 6 different wells. Under flow conditions (used for visualization), the assay was performed on two distinct days, with control strains, UAS391-Ery ${ }^{S}$ as well as Tn and complemented mutants added in duplo on the same plate. Percentages compared to UAS391-Erys ${ }^{\mathrm{S}}$ were calculated as $\mu \mathrm{m}^{2}$ area covered. In order to quantify the proportion of protein and eDNA in the biofilm matrix, pre-formed biofilms, grown under flow or no flow conditions, were rinsed once with either 1X PBS (no flow) or $0.9 \%$ sodium chloride (flow) incubated for 2 (no flow) or $5 \mathrm{~h}$ (flow) at $37^{\circ} \mathrm{C}$ with Proteinase K (Sigma-Aldrich ${ }^{\circledR}$, Merck KGaA, St. Louis, MO, USA) $(100 \mu \mathrm{g} / \mathrm{mL}$ in culture medium with $10 \mathrm{mM}$ Tris- $\mathrm{HCl}, \mathrm{pH} 7.5)$ or DNaseI (100 U/mL in culture medium) (Sigma-Aldrich ${ }^{\circledR}$, Merck KGaA, St. Louis, MO, USA). Control wells were treated with the appropriate buffer. Afterwards, the wells were washed and stained, as described before. Under no flow conditions (used for quantification), the assay was performed on three distinct days, each time on three different plates and control strains, UAS391-Ery ${ }^{S}$ as well as mutants on the same plate were added in 6 different wells. Under flow conditions (used for visualization), the assay was performed on two distinct days, with control strains, UAS391-Ery ${ }^{\mathrm{S}}$ as well as Tn, and complemented mutants added in duplo on the same plate.

\subsection{Relative Gene Expression Analysis}

To measure the impact of the Tn insertion in the target gene on the expression of the global regulator sar $A$ and on the fibronectin-binding proteins encoded by $f n b A / B, 24$ h-old no flow biofilms of Tn mutants and of UAS391-Ery ${ }^{\mathrm{S}}$ were mechanically disrupted using bead beating (FastPrep ${ }^{\circledR}-24$ classic homogenization instrument, MP Biomedicals, Irvine, CA, USA). Total RNA was isolated (Masterpure ${ }^{\mathrm{TM}}$ Complete DNA and RNA Purification kit, Epicentre ${ }^{\circledR}$, Madison, WI, USA), $1 \mu \mathrm{g}$ RNA was purified (Turbo DNA-free ${ }^{\mathrm{TM}}$, Ambion ${ }^{\circledR}$, Thermo Fisher Scientific Inc., Waltham, MA, USA) and first-strand 
cDNA was synthesized using random primers (Reverse Transcription System, Promega Corporation, Madison, WI, USA). Reverse transcriptase-PCR (RT-PCR) was performed (StepOnePlus ${ }^{\mathrm{TM}}$ system, Applied Biosystems ${ }^{\circledR}$, Thermo Fisher Scientific Inc., Waltham, MA, USA) with Power SYBR ${ }^{\mathrm{TM}}$ Green PCR Master Mix (Thermo Fisher Scientific Inc., Waltham, MA, USA). Gene-specific primers are listed in Supplementary Table S1. For data normalization, housekeeping gene gyrB (SAUSA300_0005) was used as an internal reference and the fold change in gene expression was calculated using the comparative $C_{t}$ method $\left(2^{-\Delta \Delta C t}\right)$.

\subsection{Complementation Experiments}

To confirm that the changed biofilm phenotype of the Tn mutants was caused by inactivation of the target gene and not because of secondary mutations in the genome, complementation by a cloned wild type copy of the target genes was performed. Briefly, total genomic DNA of UAS391-Ery ${ }^{S}$ was purified and the $\arg H, \operatorname{acn} A, i c d, \operatorname{glt} A, f u m C, s u c C, \operatorname{sdh} A, s d h B$, and $\operatorname{roc} F$ genes with a 25-26 bp. overlap corresponding to the nucleotide sequences flanking the EcoRI site of the shuttle vector pALC2073, were amplified, as described in Reference [17]. For genes in an operon, the distal genes were also included in the PCR fragments that were used for complementation. Primers are listed in Supplementary Table S1. PCR-fragments were cloned $\left(2 \times\right.$ Gibson Assembly ${ }^{\circledR}$ Master Mix, New England BioLabs ${ }^{\circledR}$ Inc., Ipswich, MA, USA) in the EcoRI-linearized (New England BioLabs ${ }^{\circledR}$ Inc., Ipswich, MA, USA) pALC2073 vector, transformed into recombination-impaired $\mathrm{CaCl}_{2}$-competent E. coli DH5 $\alpha$ and transformants were selected on LB supplemented with carbenicillin $(100 \mu \mathrm{g} / \mathrm{mL})$. Transformants were checked by Sanger sequencing using pALC2073 vector primers TetR2, pALC-2, and internal gene sequence primers of interest (Supplementary Table S1). Constructs were first introduced by electroporation into the restriction-deficient $S$. aureus host RN4220 to adapt plasmid DNA from E. coli to $S$. aureus modifications. Transformants were selected on LB agar plates supplemented with $10 \mu \mathrm{g} / \mathrm{mL}$ chloramphenicol (Sigma-Aldrich ${ }^{\circledR}$, Merck KGaA, St. Louis, MO, USA). Subsequently, plasmid DNAs isolated from this strain were introduced by electroporation into the corresponding UAS391-EryS Tn mutants and the transformants were again selected on LB medium supplemented with $10 \mu \mathrm{g} / \mathrm{mL}$ chloramphenicol. The expression of the cloned genes was induced by adding $0.1 \mu \mathrm{g} / \mathrm{mL}$ anhydrotetracycline (Sigma-Aldrich ${ }^{\circledR}$, Merck KGaA, St. Louis, MO, USA) to the growth media.

\subsection{Statistical Analysis}

Biomass quantification in the dynamic flow and no flow assays, as well as growth rate analysis was performed using the R Project software (version 3.1.2.) ( $R$ foundation, Vienna, Austria). A Welch two-sample $t$-test or a Wilcoxon Rank Sum test was used when data was either distributed normally or not, based on a Shapiro-Wilk Normality test. $p$-values $<0.05$ were considered significant.

\section{Results}

\subsection{Urea Cycle Mutant argH::Tn, but Not rocF::Tn, Demonstrates a Significantly Decreased Capacity for} Biofilm Formation

Comparison of average growth rates of $\operatorname{argH}:: T n$ and rocF::Tn mutants with UAS391-Erys showed no decrease in growth rates $(p=0.158$ and $p=0.207$, respectively) (Table 2 and Supplementary Figure S1). Next, no flow and flow biofilms formed by the $\arg H:: T n$ and rocF::Tn mutants were quantified compared to UAS391-Ery ${ }^{\mathrm{S}}$. The $\operatorname{argH}::$ Tn mutant showed a significant decrease in biofilm formation both in the no flow $(p<0.001)$ and in the flow model $(p=0.008)$, compared to UAS391-Ery ${ }^{S}$ (Table 2 and Figure 2). However, a similarly significant decrease was not observed with the rocF::Tn mutant ( $p \geq 0.103$ ) (Table 2 and Figure 2). The biomass under flow and no flow conditions increased for argH::Tn upon complementation with pGV5990 to quantities comparable to UAS391-Ery ${ }^{S}(p \leq 0.045)$, while the complemented rocF::Tn (with pGV6003) showed no change in biofilm formation, as compared to rocF::Tn mutant or to UAS391-Erys $(p \geq 0.057)$ (Table 2). 
Table 2. Overview of results. Quantification of formed biofilm mass (optical density, no flow assay; integrated density, dynamic assay), growth rate (growth curve assay), ratio live:dead cells (Syto ${ }^{\mathrm{TM}} 9$ Green Fluorescent Acid and propidium iodide stain), protein component (Filmtracer ${ }^{\mathrm{TM}}$ SYPRO ${ }^{\mathrm{TM}}$ Ruby Biofilm Matrix stain), and PIA/PNAG component (WGA Texas Red ${ }^{\mathrm{TM}}-\mathrm{X}$ Conjugate stain). Standard deviations are mentioned next to each value ( \pm ) and the percentage value compared to UAS391-Ery ${ }^{S}$ is mentioned between brackets. NT refers to not tested.

\begin{tabular}{|c|c|c|c|c|c|c|}
\hline Strain & $\begin{array}{l}\text { Optical Density } \\
\quad\left(\mathrm{OD}_{492}\right)\end{array}$ & $\begin{array}{l}\text { Integrated Density } \\
\text { (Fluorescence in Pixels) }\end{array}$ & $\begin{array}{l}\text { Growth Rate } \\
\left(\min ^{-1}\right)\end{array}$ & $\begin{array}{l}\text { Ratio Live:Dead } \\
\text { Cells (\%) }\end{array}$ & $\begin{array}{c}\text { Protein } \\
\text { Component (\%) }\end{array}$ & $\begin{array}{c}\text { PIA/PNAG } \\
\text { Component (\%) }\end{array}$ \\
\hline UAS391-Erys & $0.814 \pm 0.14(100 \%)$ & $11,301 \pm 61(100 \%)$ & $0.157 \pm 0.01$ & $61: 39 \pm 3: 1$ & $100 \pm 3$ & $100 \pm 6$ \\
\hline ATCC $^{\circledR} 25923^{\mathrm{TM}}$ & NT & $\mathrm{NT}$ & NT & $58: 42 \pm 13: 4$ & $34 \pm 8$ & $835 \pm 2$ \\
\hline $\arg H:: T n$ & $0.504 \pm 0.07(62 \%)$ & $3653 \pm 45(32 \%)$ & $0.161 \pm 0.01$ & $44: 56 \pm 2: 1$ & $48 \pm 10$ & $110 \pm 15$ \\
\hline $\operatorname{argH}::$ Tn with pGV5990 & $0.828 \pm 0.15(102 \%)$ & $9389 \pm 66(83 \%)$ & NT & $59: 41 \pm 16: 5$ & $83 \pm 2$ & $106 \pm 16$ \\
\hline acnA::Tn & $0.782 \pm 0.11(96 \%)$ & $651 \pm 036(58 \%)$ & $0.163 \pm 0.01$ & $61: 39 \pm 2: 1$ & $64 \pm 3$ & $77 \pm 4$ \\
\hline acnA::Tn with pGV6007 & $0.805 \pm 0.15(99 \%)$ & $773 \pm 57(68 \%)$ & NT & $60: 40 \pm 10: 3$ & $92 \pm 16$ & $101 \pm 11$ \\
\hline$i c d:: \operatorname{Tn}$ & $0.838 \pm 0.13(103 \%)$ & $8264 \pm 16(73 \%)$ & $0.166 \pm 0.01$ & $58: 42 \pm 13: 4$ & $67 \pm 4$ & $110 \pm 17$ \\
\hline icd::Tn with pGV5994 & $1.143 \pm 0.12(141 \%)$ & $8308 \pm 163(74 \%)$ & NT & $57: 43 \pm 15: 5$ & $91 \pm 3$ & $100 \pm 20$ \\
\hline icd::Tn with pGV5999 & $1.248 \pm 0.17(153 \%)$ & $8076 \pm 133(72 \%)$ & NT & $54: 46 \pm 19: 7$ & $96 \pm 22$ & $101 \pm 9$ \\
\hline gltA::Tn & $0.789 \pm 0.11(97 \%)$ & $7911 \pm 11(70 \%)$ & $0.157 \pm 0.01$ & $57: 43 \pm 18: 6$ & $61 \pm 10$ & $91 \pm 5$ \\
\hline gltA::Tn with pGV5992 & $1.102 \pm 0.12(135 \%)$ & $9616 \pm 25(85 \%)$ & NT & $61: 39 \pm 5: 2$ & $93 \pm 0$ & $100 \pm 12$ \\
\hline gltA::Tn with pGV5999 & $1.055 \pm 0.10(130 \%)$ & $8149 \pm 27(72 \%)$ & NT & $59: 41 \pm 7: 2$ & $89 \pm 9$ & $100 \pm 2$ \\
\hline fumC::Tn & $0.374 \pm 0.07(46 \%)$ & $2065 \pm 42(18 \%)$ & $0.162 \pm 0.01$ & $43: 57 \pm 1: 0$ & $49 \pm 0$ & $122 \pm 7$ \\
\hline fumC::Tn with pGV6005 & $0.941 \pm 0.14(116 \%)$ & $7662 \pm 188(68 \%)$ & NT & $66: 34 \pm 10: 3$ & $80 \pm 5$ & $100 \pm 13$ \\
\hline sucC::Tn & $0.847 \pm 0.17(104 \%)$ & $7506 \pm 58(67 \%)$ & $0.150 \pm 0.01$ & $47: 53 \pm 19: 6$ & $54 \pm 3$ & $103 \pm 17$ \\
\hline sucC:::Tn with pGV5998 & $0.804 \pm 0.11(99 \%)$ & $8715 \pm 10(77 \%)$ & NT & $65: 35 \pm 15: 5$ & $96 \pm 7$ & $101 \pm 16$ \\
\hline sucC::Tn with pGV6000 & $1.041 \pm 0.13(128 \%)$ & $7599 \pm 159(67 \%)$ & NT & $68: 32 \pm 11: 4$ & $83 \pm 2$ & $101 \pm 5$ \\
\hline $\operatorname{sdh} A:: \operatorname{Tn}$ & $0.537 \pm 0.11(66 \%)$ & $3835 \pm 60(34 \%)$ & $0.162 \pm 0.01$ & $47: 53 \pm 5: 2$ & $33 \pm 3$ & $89 \pm 8$ \\
\hline sdhA::Tn with pGV6001 & $1.002 \pm 0.10(123 \%)$ & $9002 \pm 11(80 \%)$ & NT & $51: 49 \pm 6: 2$ & $78 \pm 8$ & $101 \pm 6$ \\
\hline sdhA::Tn with pGV6002 & $1.071 \pm 0.11(132 \%)$ & $7252 \pm 092(64 \%)$ & NT & $53: 47 \pm 4: 1$ & $92 \pm 10$ & $100 \pm 11$ \\
\hline$s d h B:: \operatorname{Tn}$ & $0.667 \pm 0.10(82 \%)$ & $4875 \pm 056(43 \%)$ & $0.159 \pm 0.01$ & $48: 52 \pm 5: 2$ & $44 \pm 18$ & $84 \pm 7$ \\
\hline sdhB::Tn with pGV5996 & $0.908 \pm 0.12(112 \%)$ & $11,057 \pm 129(98 \%)$ & NT & $66: 34 \pm 6: 2$ & $106 \pm 21$ & $100 \pm 13$ \\
\hline sdhB::Tn with pGV6002 & $1.140 \pm 0.09(140 \%)$ & $8455 \pm 65(75 \%)$ & NT & $49: 51 \pm 5: 2$ & $92 \pm 3$ & $100 \pm 17$ \\
\hline rocF::Tn & $0.765 \pm 0.12(94 \%)$ & $7586 \pm 15(67 \%)$ & $0.163 \pm 0.01$ & $49: 51 \pm 5: 2$ & $51 \pm 11$ & $89 \pm 19$ \\
\hline rocF::Tn with pGV6003 & $0.878 \pm 0.09(108 \%)$ & $8342 \pm 21(74 \%)$ & NT & $65: 35 \pm 12: 4$ & $84 \pm 3$ & $101 \pm 8$ \\
\hline
\end{tabular}




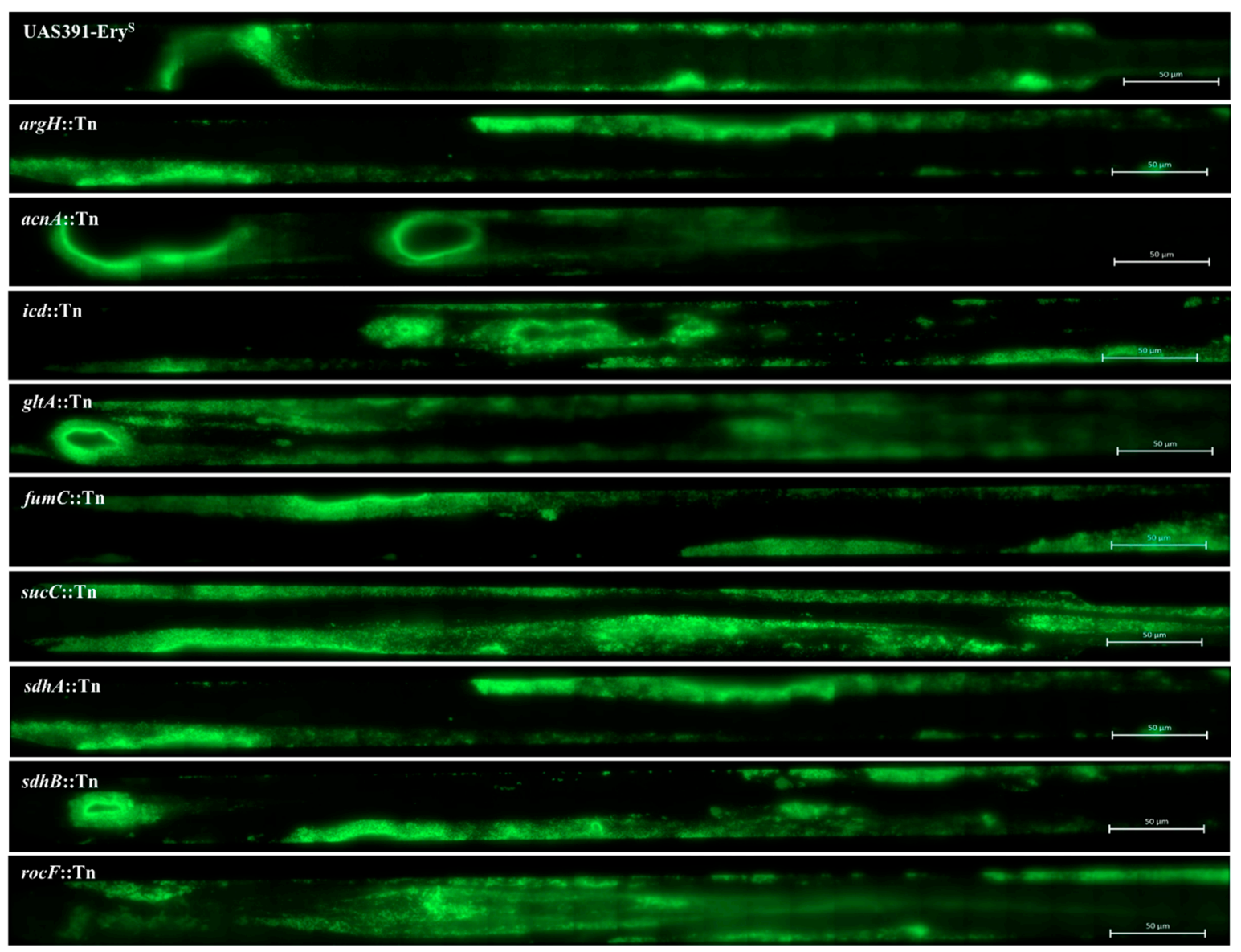

Figure 2. Effect of argininosuccinate lyase $(\arg H)$, aconitate hydratase A $(\operatorname{acn} A)$, isocitrate dehydrogenase $(i c d)$, citrate synthase II ( $g l t A)$, fumarate hydratase class II (fum $C)$, succinate-CoA ligase (subunit beta) (sucC), succinate dehydrogenase (flavoprotein subunit) (sdhA), succinate dehydrogenase iron-sulfur protein $(s d h B)$, and arginase (rocF) Tn mutants on the biofilm phenotype by UAS391-Ery ${ }^{S}$. Flow biofilm images were captured after $17 \mathrm{~h}$ growth employing ZEN 2012 software (Zeiss) as 84 combined tile images consisting of one $\mu \mathrm{m}^{2}$ horizontal tiles covering the entire microchannel.

3.2. TCA-Cycle Mutants, fumC::Tn, sdhA::Tn and sdhB::Tn, but not acnA::Tn, icd::Tn, gltA::Tn and sucC::Tn, Demonstrate a Significantly Decreased Capacity for Biofilm Formation

None of the 7 mutants tested (acnA::Tn, icd::Tn, gltA::Tn, fumC::Tn, sucC::Tn, sdhA::Tn, and $s d h B:: T n)$ displayed impaired growth rates $(p=0.554)$ (Table 2 and Supplementary Figure S1). Biofilm formation under no flow conditions decreased by 1.5 - to 2.2-fold in fumC::Tn $(p<0.001)$ and $s d h A:: \operatorname{Tn}(p<0.001)$, as compared to UAS391-Ery ${ }^{\mathrm{S}}$. Biofilm decrease was only 1.2-fold in $s d h B:: T n$ $(p=0.048)$. However, no significant decrease in biofilm formation was detected in the acnA::Tn, gltA::Tn, sucC::Tn, and icd::Tn mutants ( $p \geq 0.059$ ) (Table 2). Under flow conditions, the fumC::Tn, sdhA::Tn and $s d h B:: T n$ mutants also showed the largest decrease in biomass, compared to UAS391-Ery ${ }^{S}(p \leq 0.012)$. AcnA::Tn formed less biofilm under flow conditions $(p=0.041)$, despite not displaying any effect under no flow conditions while gltA::Tn, sucC::Tn, and icd::Tn mutants showed no significant changes in biofilm formation ( $p \geq 0.101$ ) (Table 2 and Figure 2). Biofilm formation by Tn mutants complemented with the corresponding intact gene (Table 1), showed no differences in biofilm formation, as compared to UAS391-Ery ${ }^{\mathrm{S}}$ under no flow $(p=0.423)$ or flow conditions $(p=0.053)$ (Table 2$)$. 
3.3. Fluorescent Staining of the Biofilm Matrix Reveals That the Protein Component Is Decreased in TCA-and Urea Cyle Mutants

Under flow conditions, UAS391-Ery ${ }^{S}$ biofilms showed an average live:dead cell ratio of 61\%:39\% $\pm 8 \%$, and a count of $606 \pm 15$ cells on the total imaged surface area. All 9 Tn mutants ( $\operatorname{argH}:: \operatorname{Tn}, \operatorname{acn} A:: T n, i c d:: \operatorname{Tn}$, gltA::Tn, fumC::Tn, sucC::Tn, sdhA::Tn, sdhB::Tn, and rocF::Tn, respectively) showed similar total cell numbers (609 \pm 29 , respectively) ( $p \geq 0.881)$. In contrast, the average live:dead cell ratio changed significantly for $\operatorname{argH}:: \mathrm{Tn}$, fumC::Tn, sucC::Tn, sdhA/B::Tn, and rocF::Tn $(46 \%: 54 \% \pm 3 \%)(p \leq 0.001)$, but not for acnA::Tn, icd::Tn, and $g l t A:: \operatorname{Tn}(59 \%: 41 \% \pm 2 \%)(p \geq 0.168)$ (Table 2 and Figure 3). Complemented strains showed no significant difference compared to the UAS391-Ery ${ }^{S}$ live:dead cell ratio (on average 59\%:41\% \pm 9\%) ( $p \geq 0.928$ ). Staining with WGA Texas Red $^{\text {TM}}-X$ conjugate showed $<1 \%$ total area coverage by PIA/PNAG for UAS391-Ery ${ }^{S}$, as well as for all 9 Tn mutants and for their corresponding complemented strains ( $p \geq 0.943$ ) (Table 2 and Figure 3). In contrast, WGA staining of the PIA/PNAG producing MSSA control strain ATCC ${ }^{\circledR} 25923^{\mathrm{TM}}$ (image not shown) gave a total area coverage of $91 \% \pm 2 \%$ (Table 2). Staining with FilmTracer ${ }^{\mathrm{TM}} \mathrm{SYPRO}^{\circledR}$ Ruby Biofilm Matrix Stain showed an average area coverage decrease of $48 \% \pm 19 \%$ compared to that of UAS391-Ery ${ }^{S}$ for $\operatorname{argH}:: \operatorname{Tn}$, acnA::Tn, icd::Tn, gltA::Tn, fumC::Tn, sucC::Tn, sdhA/B::Tn, and rocF::Tn $(p \leq 0.001)$ (Table 2). Complemented mutants showed similar average protein proportions of the biofilm matrix, as compared to UAS391-Ery ${ }^{\mathrm{S}}(105 \% \pm 7 \%)(p \geq 0.194)$

\subsection{Enzymatic Digest Correlates BIOFILM-Defective Transposon Mutants with a Protein- and eDNA-Based Matrix}

Under no flow conditions, the $24 \mathrm{~h}$ biomass of UAS391-Ery ${ }^{\mathrm{S}}$ grown decreased by $22 \% \pm 3 \%$ following proteinase $\mathrm{K}$ and $44 \% \pm 5 \%$ following DNase I treatment (both $p<0.001$ ), while the biomass of ATCC $^{\circledR} 25923^{\mathrm{TM}}$ S. aureus decreased by only $11 \% \pm 3 \%$ and $6 \% \pm 2 \%$, respectively $(p \geq 0.134)$ (Figure 4A,B). Under flow conditions, the 17h biomass of UAS391-Ery ${ }^{S}$ decreased by $25 \% \pm 7 \%$ following proteinase $\mathrm{K}$ and $53 \% \pm 9 \%$ following DNase I treatment $(p \leq 0.028)$, while that of ATCC $^{\circledR}$ $25923^{\mathrm{TM}}$ S. aureus decreased by only $19 \% \pm 8 \%$ and $12 \% \pm 7 \%$, respectively $(p \geq 0.145)$ (Figure 4C,D). After proteinase $\mathrm{K}$ treatment under no flow conditions, argH::Tn, acnA::Tn, icd::Tn, gltA::Tn, fumC::Tn, sucC::Tn, sdhA/B::Tn, and rocF::Tn showed on average $50 \% \pm 12 \%$ reduction in biomass compared to the untreated biofilms of the corresponding mutants ( $p \leq 0.001$ ) (Figure 4A). Similarly, after proteinase $\mathrm{K}$ treatment under flow conditions, there was an average of $51 \% \pm 8 \%(p \leq 0.05)$ (Figure $4 \mathrm{C}$ ). After DNase I treatment under no flow conditions, argH::Tn, acnA::Tn, icd::Tn, gltA::Tn, fumC::Tn, sucC::Tn, sdhA/B::Tn, and rocF::Tn showed an average $55 \% \pm 10 \%$ reduction in biofilm mass as compared to the untreated biofilms of the corresponding mutants. ( $p \leq 0.005)$ (Figure $4 \mathrm{~B}$ ). Similarly, after DNase I treatment under flow conditions, there was a reduction of $52 \% \pm 10 \%$ respectively $(p \leq 0.05)$ (Figure 4D). Complemented strains showed an average biomass decrease of $23 \% \pm 6 \%$ and $48 \% \pm 10 \%$ after both treatments under flow and no flow conditions $(p<0.001)$, which is comparable to results obtained with UAS391-Erys .

In all TCA- and urea cycle Tn mutants, sarA showed a distinct upregulation (1.35 to 3.63-fold), with the exception of sucC::Tn, which showed a 0.92-fold downregulation (Supplementary Figure S2). Overall, a knockout mutation in either the TCA- or urea cycle was associated with a decrease in $f n b A$ and $f n b B$ expression (0.53- to 0.78-fold and 0.51 to 0.77-fold, respectively) (Supplementary Figure S2). 


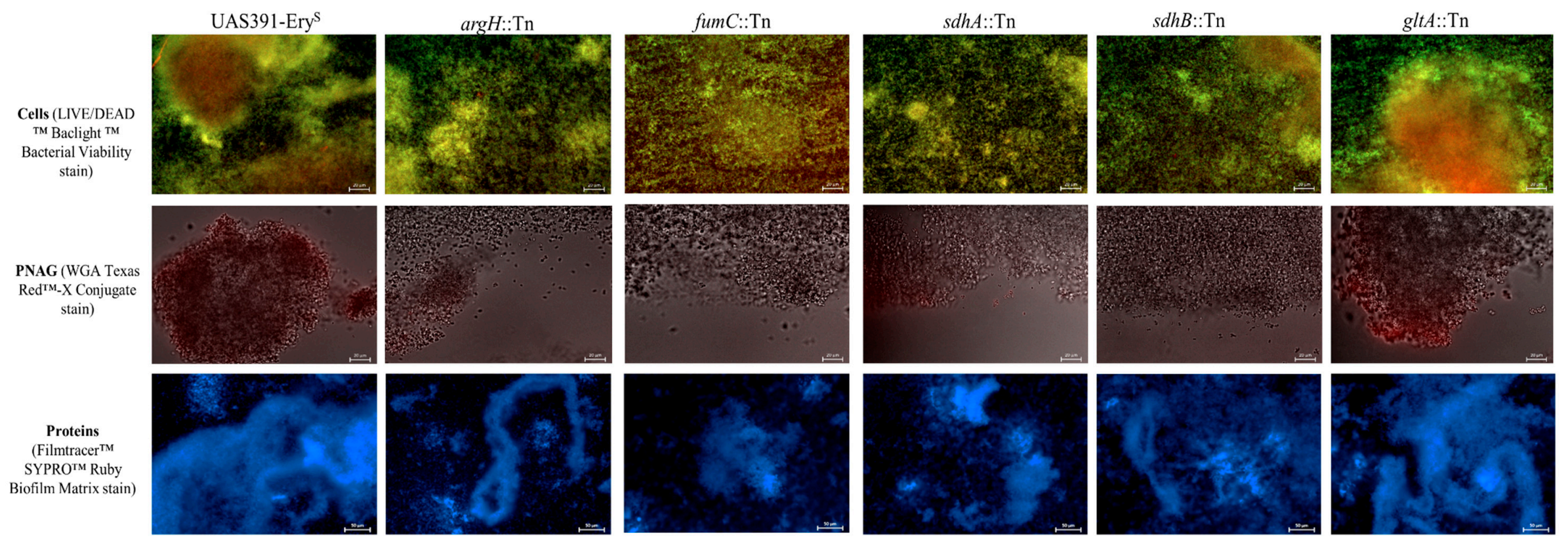

Figure 3. Fluorescence microscopy observations of no flow biofilm matrix structure obtained from UAS391-Ery ${ }^{\mathrm{S}}$, argininosuccinate lyase (argH), fumarate hydratase class II (fumC), succinate dehydrogenase (flavoprotein subunit) ( $(\mathrm{d} h \mathrm{~A})$, succinate dehydrogenase iron-sulfur protein (sdhB), and citrate synthase II (glt $A$ ) Tn mutants. Since microscopy images of gltA::Tn, acnA::Tn, icd::Tn, sucC::Tn, and rocF::Tn, as well as corresponding complemented mutant biofilms were comparable to each other, the matrix formed by gltA::Tn serves as an example picture for all. The top row shows total cells stained with SYTO 9 TM 9 and PI. The middle row shows PNAG stained with WGA Texas Red ${ }^{\mathrm{TM}}-\mathrm{X}$ Conjugate, and is combined with Bright-field imaging. The bottom row shows the protein component stained with FilmTracer ${ }^{\mathrm{TM}}$ SYPRO ${ }^{\mathrm{TM}}$ Ruby Biofilm Matrix. 

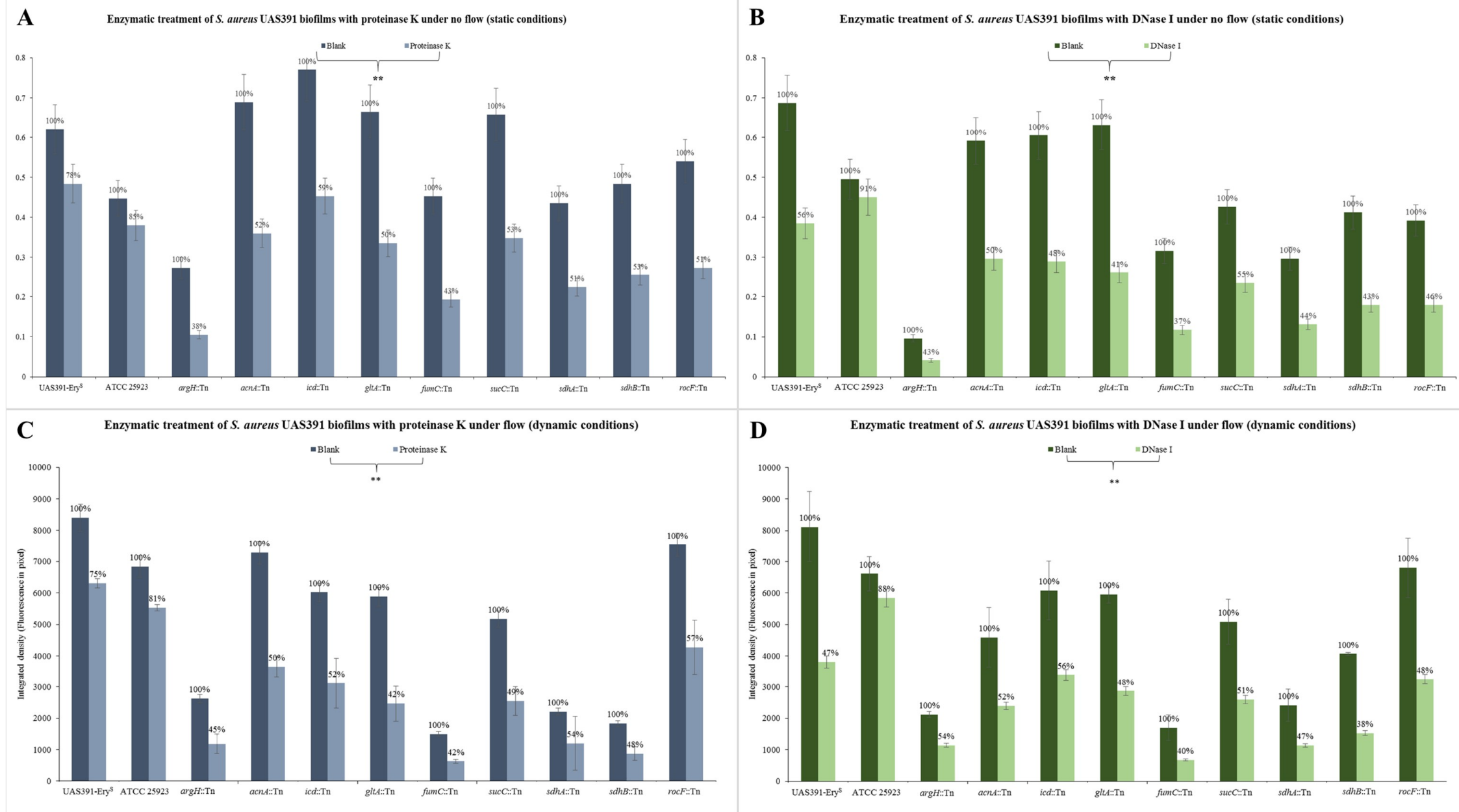

Figure 4. Enzymatic treatment of preformed 24 (no flow) or 17 (flow) h-old biofilms of UAS391-Ery ${ }^{\mathrm{S}}$, ATCC ${ }^{\circledR} 25923^{\mathrm{TM}}$ and urea or TCA-cycle Tn mutants with $100 \mathrm{\mu g} / \mathrm{mL}$ proteinase $\mathrm{K}(\mathbf{A}, \mathbf{C})$ or $100 \mathrm{U} / \mathrm{mL}$ DNase I (B,D) under no flow (no flow) (A,B) and dynamic (flow) (C,D) conditions. Blanks refer to incubation in either culture medium with $10 \mathrm{mM}$ Tris- $\mathrm{HCl}$ for proteinase $\mathrm{K}$ treatment or culture medium for DNase I treatment. Error bars represent $95 \%$ confidence intervals. ${ }^{* *}$ refers to $p<0.001$. 


\section{Discussion}

The biofilm matrix of MRSA-USA300 and corresponding Tn mutants is PIA/PNAG-independent and mainly composed of proteins and eDNA.

Using enzymatic digest and biofilm-matrix staining experiments to assess the contribution of PIA/PNAG, protein, and eDNA to the biofilm matrix of MRSA-USA300, we firstly showed that the biofilm matrix of USA300 UAS391-Ery ${ }^{S}$ and Tn mutants was primarily composed of proteinaceous material and eDNA with $<1 \%$ contribution of PIA/PNAG. Interestingly, and in contrast to MSSA, inactivation of the TCA-cycle in MRSA Tn mutants did not result in any increase of PIA/PNAG in the biofilm matrix. In MSSA, decreased TCA-cycle activity was reported to shunt metabolites toward PIA/PNAG production [14]. We have previously whole genome sequenced the UAS391 strain and found an intact functional icaADBC operon [19]. These data fully support the results of Pozzi et al. that showed that high level expression of PBP2a - the product of the methicillin resistance gene, $m e c A$, harboured on the SCCmec element that differentiates MRSA and MSSA-blocks icaADBC-dependent polysaccharide biofilm development and promotes formation of proteinaceous biofilms [5]. Of note, S. aureus also produces a capsular polysaccharide (type 5 and 8), which has been implicated in biofilm formation [24]. The role of the TCA-cycle in capsular polysaccharide production was demonstrated by Sadykov et al. who showed that in the absence of glucose, the capsular sugar precursor fructose 6-phoshate is synthesized by gluconeogenesis from the TCA-cycle intermediate oxaloacetate [25]. However, the USA300 clonal lineage, including the UAS391 strain, harbors conserved mutations in the cap5 locus, and does not produce a capsular polysaccharide [26], which also made it easier to exclude the contribution of PIA/PNAG to the biofilm matrix of UAS391 and its Tn mutants.

\subsection{TCA-Cycle Inactivation Impacts the Protein Component of the Biofilm Matrix of MRSA-USA300}

Upon comparison of the net protein contribution to the matrix under no flow and flow conditions, it was clear that the net contribution of proteins to the entire Tn mutant biomass (on average $50 \%$ and $51 \%$, respectively) was significantly higher than for UAS391-Ery ${ }^{\mathrm{S}}$ (on average $22 \%$ and $25 \%$, respectively).

Several studies have reported a role for proteins and eDNA in the ica-independent MRSA biofilm phenotype $[8,9,27]$. Houston et al. demonstrated an important role for eDNA during the primary attachment and early stages of MRSA biofilm formation by employing a $\Delta a t l$ knockout mutant in MRSA isolate BH1CC [9]. These authors also reported that DNaseI impaired biofilm development by MRSA isolates from clonal complex 5 (CC5), CC22 and sequence type 239 (ST239). Moreover, treatment of USA300 biofilms after $6 \mathrm{~h}$ and $22 \mathrm{~h}$ of growth demonstrated both a significant impact of DNaseI and proteinase $\mathrm{K}$, with the latter having the largest impact on the total biofilm mass [27]. Our results also indicate the possibility of the USA300 biofilm matrix containing other components, as protein and eDNA only accounted for on average $23.5 \%$ and $48.5 \%$ of the biomass. These might have been teichoic acids associated with the cell wall (cell wall teichoic acid, WTA) or cell membrane (lipoteichoic acid, LTA) [28].

A prior study on an ica-knockout MSSA strain RN6390 has shown that, in the presence of citrate, the fibronectin-binding proteins, FnBPA and FnBPB, stimulate biofilm formation by promoting both cell-to-surface and cell-to-cell interactions, which is part of a larger network of virulence factors that are controlled by the staphylococcal accessory regulator, SarA [29]. All urea and TCA-cycle Tn mutants in our study showed a significant downregulation in $f n b A$ and $f n b B$ gene expression compared to UAS391-Ery ${ }^{S}$, whereas sarA was upregulated for all Tn mutants except sucC::Tn. SarA has been reported to work synergistically with the two-component saeRS system to repress extracellular proteases that would otherwise reduce the accumulation of critical proteins that contribute to the biofilm matrix [30]. Downregulation of $f n b A$ /B would potentially lead to a decreased protein biofilm matrix, but upregulation of sarA might neutralize and counteract this effect in the Tn mutants. 


\subsection{Inactivation of Specific TCA-Cycle Genes Is Associated with a High Metabolic Fitness Cost}

Using live-dead staining on flow biofilms, we found a significantly higher amount of dead cells in the biofilms formed by $\operatorname{argH::Tn}$, fumC::Tn, sdhA::Tn, sdhB::Tn, sucC::Tn, and rocF::Tn mutants. However, these mutants neither demonstrated attenuated or slower growth on growth curve assays nor were the total number of cells in their respective biofilms significantly different from those in UAS-391-Erys biofilms. However, Halsey et al. have shown that Tn mutants with mutations in TCA-cycle genes past the 2-oxoglutarate node (fumC, $s d h A$, and $s u c C)$ did not grow at all in their planktonic $S$. aureus growth assay [31]. The fact that these defects were not detected in our corresponding TCA-cycle Tn mutants might be due to differences in growth media.

A higher number of dead cells found in the biofilms of Tn mutants might be indicative of a high metabolic cost for the bacterium. It is important to note that propidium iodide does not only stain cells with a compromised membrane, but also eDNA. However, the proportion of eDNA in the biofilm matrix, observed by DNase I digestion, did not differ significantly between the Tn mutants (on average $52 \%$ and 55\% under flow and no flow conditions, respectively) and UAS391-Ery ${ }^{S}$ (on average $44 \%$ and $53 \%$ under flow and no flow conditions, respectively). Thus, based on our data, inactivation of the TCA-cycle is likely not associated with any change in eDNA biofilm matrix composition.

In conclusion, we identified an important role of the TCA-cycle in mediating biofilm formation, specifically by influencing the matrix composition, in MRSA USA300 biofilms. These metabolic pathway hits require further screening of MRSA of different clonal lineages to confirm commonality of the target mechanisms and eventually yield interesting therapeutic targets.

Supplementary Materials: The following are available online at http:/ www.mdpi.com/2076-2607/6/4/113/s1, Figure S1: Background absorption-corrected 24h growth curves for UAS391-Ery ${ }^{\mathrm{S}}$ as well as $\operatorname{argH}:: \mathrm{Tn}, \operatorname{acn} A:: \mathrm{Tn}$, icd::Tn, gltA::Tn, fumC::Tn, sucC::Tn, sdhA::Tn, sdhB::Tn and rocF::Tn mutants. Error bars in corresponding color represent the $95 \%$ confidence interval per strain; Figure S2: Relative quantification of $f n b A, f n b B$ and sarA gene expression in UAS391-Ery ${ }^{\mathrm{S}}$ and the corresponding TCA- and urea cycle knockout mutants, normalized to gyrB expression and calculated using the Comparative $C_{t}$ Method $\left(2^{-\Delta \Delta C t}\right)$. Gene expression in UAS391-Ery ${ }^{S}$ was taken as baseline 0; Table S1: Primers used during this study. Primers were designed against S. aureus strain USA300-UAS391 (\#CP007690.1).

Author Contributions: Conceptualization, J.S., H.D.G., J.-P.H., H.G. and S.M.-K.; Investigation, S.D.B.; Methodology, J.S. and I.D.P.; Writing—original draft, S.D.B.; Writing—review \& editing, S.D.B. and S.M.-K. All authors read, gave input and approved the final manuscript.

Funding: SDB is supported by funding from Research Foundation Flanders (FWO, applicant number 1128818N). The described research is part of IWT-SBO project (\#140746) and FWO research project (\#GOD3516N).

Acknowledgments: We thank Francine Deboeck for excellent technical assistance during the complementation experiments.

Conflicts of Interest: The authors declare that they have no competing interests.

\section{References}

1. Lee, A.S.; de Lencastre, H.; Garau, J.; Kluytmans, J.; Malhotra-Kumar, S.; Peschel, A.; Harbarth, S. Methicillin-resistant Staphylococcus aureus. Nat. Rev. Dis. Primers 2018, 4, 18033. [CrossRef] [PubMed]

2. Archer, N.K.; Mazaitis, M.J.; Costerton, J.W.; Leid, J.G.; Powers, M.E.; Shirtliff, M.E. Staphylococcus aureus biofilms: Properties, regulation, and roles in human disease. Virulence 2011, 2, 445-459. [CrossRef] [PubMed]

3. Fitzpatrick, F.; Humphreys, H.; O'Gara, J.P. Environmental regulation of biofilm development in methicillin-resistant and methicillin-susceptible Staphylococcus aureus clinical isolates. J. Hosp. Infect. 2006, 62, 120-122. [CrossRef] [PubMed]

4. O'Neill, E.; Pozzi, C.; Houston, P.; Smyth, D.; Humphreys, H.; Robinson, D.A.; O'Gara, J.P. Association between methicillin susceptibility and biofilm regulation in Staphylococcus aureus isolates from device-related infections. J. Clin. Microbiol. 2007, 45, 1379-1388. [CrossRef] [PubMed]

5. O'Gara, J.P. Ica and beyond: Biofilm mechanisms and regulation in Staphylococcus epidermidis and Staphylococcus aureus. FEMS Microbiol. Lett. 2007, 270, 179-188. [CrossRef] [PubMed] 
6. Pozzi, C.; Waters, E.M.; Rudkin, J.K.; Schaeffer, C.R.; Lohan, A.J.; Tong, P.; Loftus, B.J.; Pier, G.B.; Fey, P.D.; Massey, R.C.; et al. Methicillin resistance alters the biofilm phenotype and attenuates virulence in Staphylococcus aureus device-associated infections. PLoS Pathog. 2012, 8, e1002626. [CrossRef] [PubMed]

7. O'Neill, E.; Pozzi, C.; Houston, P.; Humphreys, H.; Robinson, D.A.; Loughman, A.; Foster, T.J.; O'Gara, J.P. A novel Staphylococcus aureus biofilm phenotype mediated by the fibronectin-binding proteins, FnBPA and FnBPB. J. Bacteriol. 2008, 190, 3835-3850. [CrossRef] [PubMed]

8. Izano, E.A.; Amarante, M.A.; Kher, W.B.; Kaplan, J.B. Differential roles of poly- $N$-acetylglucosamine surface polysaccharide and extracellular DNA in Staphylococcus aureus and Staphylococcus epidermidis biofilms. Appl. Environ. Microbiol. 2008, 74, 470-476. [CrossRef] [PubMed]

9. Houston, P.; Rowe, S.E.; Pozzi, C.; Waters, E.M.; O'Gara, J.P. Essential role for the major autolysin in the fibronectin-binding protein-mediated Staphylococcus aureus biofilm phenotype. Infect. Immun. 2011, 79, 1153-1165. [CrossRef] [PubMed]

10. Mann, E.E.; Rice, K.C.; Boles, B.R.; Endres, J.L.; Ranjit, D.; Chandramohan, L.; Tsang, L.H.; Smeltzer, M.S.; Horswill, A.R.; Bayles, K.W. Modulation of eDNA release and degradation affects Staphylococcus aureus biofilm maturation. PLoS ONE 2009, 4, e5822. [CrossRef] [PubMed]

11. Rice, K.C.; Mann, E.E.; Endres, J.L.; Weiss, E.C.; Cassat, J.E.; Smeltzer, M.S.; Bayles, K.W. The cidA murein hydrolase regulator contributes to DNA release and biofilm development in Staphylococcus aureus. Proc. Natl. Acad. Sci. USA 2007, 104, 8113-8118. [CrossRef] [PubMed]

12. Sonenshein, A.L. The Krebs Citric Acid Cycle; ASM Press: Washington, DC, USA, 2002.

13. Sadykov, M.R.; Olson, M.E.; Halouska, S.; Zhu, Y.; Fey, P.D.; Powers, R.; Somerville, G.A. Tricarboxylic acid cycle-dependent regulation of Staphylococcus epidermidis polysaccharide intercellular adhesin synthesis. J. Bacteriol. 2008, 190, 7621-7632. [CrossRef] [PubMed]

14. Vuong, C.; Kidder, J.B.; Jacobson, E.R.; Otto, M.; Proctor, R.A.; Somerville, G.A. Staphylococcus epidermidis polysaccharide intercellular adhesin production significantly increases during tricarboxylic acid cycle stress. J. Bacteriol. 2005, 187, 2967-2973. [CrossRef] [PubMed]

15. Zhu, Y.; Xiong, Y.Q.; Sadykov, M.R.; Fey, P.D.; Lei, M.G.; Lee, C.Y.; Bayer, A.S.; Somerville, G.A. Tricarboxylic acid cycle-dependent attenuation of Staphylococcus aureus in vivo virulence by selective inhibition of amino acid transport. Infect. Immun. 2009, 77, 4256-4264. [CrossRef] [PubMed]

16. Fey, P.D.; Endres, J.L.; Yajjala, V.K.; Widhelm, T.J.; Boissy, R.J.; Bose, J.L.; Bayles, K.W. A genetic resource for rapid and comprehensive phenotype screening of nonessential Staphylococcus aureus genes. MBio 2013, 4, e00537-00512. [CrossRef] [PubMed]

17. Sabirova, J.S.; Hernalsteens, J.P.; De Backer, S.; Xavier, B.B.; Moons, P.; Turlej-Rogacka, A.; De Greve, H.; Goossens, H.; Malhotra-Kumar, S. Fatty acid kinase A is an important determinant of biofilm formation in Staphylococcus aureus USA300. BMC Genom. 2015, 16, 861. [CrossRef] [PubMed]

18. Vanhommerig, E.; Moons, P.; Pirici, D.; Lammens, C.; Hernalsteens, J.P.; De Greve, H.; Kumar-Singh, S.; Goossens, H.; Malhotra-Kumar, S. Comparison of biofilm formation between major clonal lineages of methicillin-resistant Staphylococcus aureus. PLoS ONE 2014, 9, e104561. [CrossRef] [PubMed]

19. Sabirova, J.S.; Xavier, B.B.; Hernalsteens, J.P.; De Greve, H.; Ieven, M.; Goossens, H.; Malhotra-Kumar, S. Complete genome sequences of two prolific biofilm-forming Staphylococcus aureus isolates belonging to USA300 and EMRSA-15 clonal lineages. Genome Announc. 2014, 2. [CrossRef] [PubMed]

20. Luppens, S.B.I.; Reij, M.W.; van der Heijden, R.W.L.; Rombouts, F.M.; Abee, T. Development of a standard test to assess the resistance of Staphylococcus aureus biofilm cells to disinfectants. Appl. Environ. Microbiol. 2002, 68, 4194-4200. [CrossRef] [PubMed]

21. Somerville, G.A.; Proctor, R.A. At the crossroads of bacterial metabolism and virulence factor synthesis in Staphylococci. Microbiol. Mol. Biol. Rev. 2009, 73, 233-248. [CrossRef] [PubMed]

22. Bateman, B.T.; Donegan, N.P.; Jarry, T.M.; Palma, M.; Cheung, A.L. Evaluation of a tetracycline-inducible promoter in Staphylococcus aureus in vitro and in vivo and its application in demonstrating the role of sigB in microcolony formation. Infect. Immun. 2001, 69, 7851-7857. [CrossRef] [PubMed]

23. Hall, B.G.; Acar, H.; Nandipati, A.; Barlow, M. Growth rates made easy. Mol. Biol. Evol. 2014, 31, $232-238$. [CrossRef] [PubMed]

24. O’Riordan, K.; Lee, J.C. Staphylococcus aureus Capsular Polysaccharides. Clin. Microbiol. Rev. 2004, 17, 218-234. [CrossRef] [PubMed] 
25. Sadykov, M.R.; Mattes, T.A.; Luong, T.T.; Zhu, Y.; Day, S.R.; Sifri, C.D.; Lee, C.Y.; Somerville, G.A. Tricarboxylic acid cycle-dependent synthesis of Staphylococcus aureus type 5 and 8 capsular polysaccharides. J. Bacteriol. 2010, 192, 1459-1462. [CrossRef] [PubMed]

26. Boyle-Vavra, S.; Li, X.; Alam, M.T.; Read, T.D.; Sieth, J.; Cywes-Bentley, C.; Dobbins, G.; David, M.Z.; Kumar, N.; Eells, S.J.; et al. USA300 and USA500 clonal lineages of Staphylococcus aureus do not produce a capsular polysaccharide due to conserved mutations in the cap5 locus. MBio 2015, 6. [CrossRef] [PubMed]

27. Lauderdale, K.J.; Malone, C.L.; Boles, B.R.; Morcuende, J.; Horswill, A.R. Biofilm dispersal of community-associated methicillin-resistant Staphylococcus aureus on orthopedic implant material. J. Orthop. Res. 2010, 28, 55-61. [CrossRef] [PubMed]

28. Otto, M. Staphylococcal biofilms. Curr. Top. Microbiol. Immunol. 2008, 322, 207-228. [PubMed]

29. Shanks, R.M.; Meehl, M.A.; Brothers, K.M.; Martinez, R.M.; Donegan, N.P.; Graber, M.L.; Cheung, A.L.; O'Toole, G.A. Genetic evidence for an alternative citrate-dependent biofilm formation pathway in Staphylococcus aureus that is dependent on fibronectin binding proteins and the GraRS two-component regulatory system. Infect. Immun. 2008, 76, 2469-2477. [CrossRef] [PubMed]

30. Mrak, L.N.; Zielinska, A.K.; Beenken, K.E.; Mrak, I.N.; Atwood, D.N.; Griffin, L.M.; Lee, C.Y.; Smeltzer, M.S. saeRS and sarA act synergistically to repress protease production and promote biofilm formation in Staphylococcus aureus. PLoS ONE 2012, 7, e38453. [CrossRef] [PubMed]

31. Halsey, C.R.; Lei, S.; Wax, J.K.; Lehman, M.K.; Nuxoll, A.S.; Steinke, L.; Sadykov, M.; Powers, R.; Fey, P.D. Amino acid catabolism in Staphylococcus aureus and the function of carbon catabolite repression. MBio 2017, 8. [CrossRef] [PubMed]

(c) 2018 by the authors. Licensee MDPI, Basel, Switzerland. This article is an open access article distributed under the terms and conditions of the Creative Commons Attribution (CC BY) license (http:/ / creativecommons.org/licenses/by/4.0/). 